\title{
ANTIFUNGAL EFFECT OF SELECTED ESSENTIAL OILS ON MALASSEZIA PACHYDERMATIS GROWTH
}

\author{
Váczi, P., Čonková, E., Marcinčáková, D., Sihelská, Z. \\ Institute of Pharmacology, Department of Pharmacology and Toxicology \\ University of Veterinary Medicine and Pharmacy, Komenského 73, 04181 Košice \\ Slovakia \\ peter.vaczi@uvlf.sk
}

\section{ABSTRACT}

The antifungal activities of 14 selected essential oils (at the concentrations of $0.5 \%, 5 \%$, and $30 \%$ ) against the yeast Malassezia pachydermatis (18 isolates and one reference strain) were investigated. The isolates of $M$. pachydermatis were obtained from swabs of external ear canals of healthy dogs using sterile swabs. The determination of the efficacy was based on a modified disc diffusion method (CLSI M44-A2). The best antifungal efficacy (100\%) was shown by clove, cinnamon and oregano at the concentration of $30 \%$; less significant efficacy was shown at the concentration of $5 \%(38 \%, 33 \%$ and $5 \%$, respectively). Satureja inhibited the growth of Malassezia (efficacy of 16\%) only at the concentration of $30 \%$. Bergamot, lavender, juniper, cedar, sage, tea-tree, grapefruit, pine, chamomile and yarrow essential oils were not able to form inhibition zones as defined in the methodology used (greater or equal to $15 \mathrm{~mm}$ ) in all concentrations used. Therefore, according to the interpretation criterion, they were considered ineffective. In all cases, the concentration of $0.5 \%$ was not effective against the growth of Malassezia yeasts.
Key words: dog; essential oil; disc diffusion method; Malassezia; sensitivity

\section{INTRODUCTION}

Malassezia yeasts are eukaryotic microorganisms placed in the phylum Basidiomycota [12]. Currently, the genus Malassezia includes sixteen species, fifteen of which are lipid-dependent and are most frequently recovered from humans, ruminants, horses or parrots (Malassezia furfur, M.globosa, M. obtusa, M. restricta, M. slooffiae, M. sympodialis, M.dermatis, M.nana, M.japonica, M. yamatoensis, M.equina, M.caprae, M.cuniculi, M.brasiliensis and M.psittaci). The only one non-lipid-dependent species, M. pachydermatis, is commonly recovered from dogs and cats $[1,2,3,4,27]$.

M.pachydermatis is a saprophytic and lipophilic yeast, which is part of the normal cutaneous microflora of several warm-blooded animals [20]. It is often found in the ear canals and skin of dogs, cats and other species of domestic and wild animals $[14,15]$. M.pachydermatis is frequently 
involved as a secondary factor in canine otitis externa and skin infections, which are manifested by irregularly superficial to interstitial dermatitis wherein hyperkeratosis and lymphocytic exocytosis are prominent $[7,19]$.

At the present, the therapy of malassezia-dermatitis is usually based on topical or systemic administration of antifungals (mainly those of azoles) and direct topical application of antiseptic substances. An alternative and attractive possibility of supportive therapy is the use of essential oils.

Essential oils (EOs) are concentrated, hydrophobic substances containing volatile aroma compounds from different parts of plants extracted by steam distillation and by various solvents $[21,22]$. The main constituents of essential oils - mono- and sesquiterpenes including carbohydrates, alcohols, ethers, aldehydes and ketones - are responsible for the fragrant and biological properties of aromatic and medicinal plants. Various EOs produce pharmacological effects, demonstrating anti-inflammatory, antioxidant and anti-carcinogenic properties [16].

On the basis of the results obtained in the preliminary study [25], the main objective of this study was to determine the effectiveness of the selected EOs in three different concentrations $(0.5 \%, 5 \%$ and $30 \%)$ against M.pachydermatis isolated from the external ear canals of healthy dogs.

\section{MATERIALS AND METHODS}

Phenotypic and genotypic identification of Malassezia pachydermatis.

Isolates $(\mathrm{n}=18)$ of M.pachydermatis were obtained from swabs of external ear canals of healthy dogs. The identification of yeasts was performed on the basis of detailed phenotypic features according to Kaneko et al. [17] and confirmed by genotypic PCR methods according to Gaitanis and Velegraki [13].

\section{Selection and composition of essential oils}

Essential oils of the following medicinal plants were tested: bergamot, cedar, chamomile, cinnamon, clove, grapefruit, juniper, lavender, oregano, pine, sage, satureja winter savory, tea tree and common yarrow. The EOs were obtained from the Calendula company (Nová Lubovňa, Slovakia) as pure substances (concentration of $100 \%$ ) and their composition is listed in Table 1. Three concentrations were used: $0.5 \%, 5 \%$ and $30 \%$. Mineral oil - liquid paraffin (Merck KGaA, Darmstadt, Germany) was chosen to dilute the pure essential oils to the required concentrations. It was selected for its inertness so as to prevent the false positivity (antifungal activity of the diluent itself). Pure and

Table 1. Composition of the essential oils according to the producer (Calendula company, Nová Lubovňa, Slovakia)

\begin{tabular}{|c|c|c|}
\hline Essential oil & Plant of origin & Content substances \\
\hline Bergamot & Citrus bergamia & limonene $36 \%$, linalool $15 \%$, linalyl acetate $23 \%$ \\
\hline Cedar & Cedrus spp. & cineol $30 \%$, thujone $3 \%$, borneol $3 \%$ \\
\hline Chamomile & Matricaria recucita & bisabolol oxides $5 \%$, bisabolol $29 \%$, chamazulene $2.7 \%$ \\
\hline Cinnamon & Cinnamonum aromaticum & eugenol $77 \%$ \\
\hline Clove & Syzygium aromaticum & eugenol $85 \%$ \\
\hline Grapefruit & Citrus paradisi & limonene $87 \%$ \\
\hline Juniper & Juniperus communis & $\begin{array}{l}\text { a-pinene } 45 \% \text {, sabinene } 2 \% \text {, } \beta \text {-pinene } 4 \% \text {, } \\
\beta \text {-myrcene } 3.5 \% \text {, a-phellandrene }<1 \% \text {, limonene } 13 \% \text {, terpinen-4-ol } 0.5 \% \text {, bornyl acetate }<1 \% \text {, } \\
\beta \text {-karyophylene } 2 \%\end{array}$ \\
\hline Lavender & Lavandula angustifolia & linalool $43 \%$ \\
\hline Oregano & Origanum vulgare & carvacrol $57 \%$ \\
\hline Pine & Pinus sylvestris & $\begin{array}{l}\text { a-pinene } 43 \% \text {, camphene } 1.5 \%, \beta \text {-pinene } 19 \% \text {, car-3-ene } 17 \%, \beta \text {-myrcene } 2.2 \% \text {, limonene } 8 \% \text {, } \\
\beta \text {-phellandrene }<2.5 \% \text {, p-cymene }<2 \% \text {, terpinolene }<4 \% \text {, bornyl acetate } 2.3 \% \text {, } \\
\beta \text {-karyophylene } 2.5 \%\end{array}$ \\
\hline Sage & Salvia officinalis & cineol $15 \%$, thujone $24 \%$, borneol $18 \%$ \\
\hline Satureja & Satureja montana & not established \\
\hline Tea-tree & Melaleuca alternifolia & terpinen-4-ol $33 \%$ \\
\hline Yarrow & Achillea millefolium & chamazulene $6 \%$ \\
\hline
\end{tabular}


also diluted EOs were stored under standard laboratory conditions $\left(18^{\circ} \mathrm{C}\right)$ and without access of light (wrapped in aluminium foil).

\section{Testing of sensitivity}

The sensitivity of 18 isolates and one reference strain of M. pachydermatis (CBS 1879, CBS-KNAW Fungal Biodiversity Centre, Utrecht, Netherlands) was evaluated by a modified disc diffusion method M44-A2 [9]. The method is based on pathogen growth inhibition, manifested by the development of diffusion zone due to the release of the antifungal substances from impregnated paper discs. A reference strain of $M$.pachydermatis was used as a control.

In the experiment, 7-day old cultures of M.pachydermatis passaged on Sabouraud dextrose agar with chloramphenicol - SCA (Himedia Laboratories Pvt. Ltd., India) were used. The yeast suspension was prepared in physiologic saline solution supplemented with $0.1 \%$ of Tween 80 (Merck KGaA, Darmstadt, Germany) at the final concentration of $10^{6} \mathrm{CFU} . \mathrm{ml}^{-1}$ corresponding to the standard 1 on a McFarland scale. The suspension was inoculated by using a sterile swab onto agar plates containing nutrient medium - SCA, twice in three directions, 15 minutes apart. Paper discs (Oxoid Ltd., United Kingdom) were applied to the surface of the agar. Each disc (6 $\mathrm{mm}$ in diameter) was impregnated with $15 \mu \mathrm{l}$ of the respective essential oil (concentration of $30 \%, 5 \%$ and $0.5 \%$ in liquid paraffin). The cultivation took place at a constant temperature of $32{ }^{\circ} \mathrm{C}$ for 96 hours. Subsequently, the size of the inhibitory zone was measured by using an Antibiotic zone scale (Himedia Laboratories Pvt. Ltd., India). Since the method M44-A2 is intended for Candida species [9] and does not include interpretation criteria for Malassezia strains, isolates that showed an inhibition zone greater or equal to $15 \mathrm{~mm}$ (2.5fold larger than the disc diameter) were considered to be sensitive.

The validity of testing was confirmed on the basis of the sensitivity of Candida albicans reference strain CCM 8261 (Czech Collection of Microorganisms, Brno, Czech Republic) to itraconazole (10 mg per disc; Himedia Laboratories Pvt. Ltd., India). The inhibition zone of $20 \mathrm{~mm}$ was detected, which is in agreement with interpretation criteria specified in the methodology $(18-20 \mathrm{~mm})$.

The antifungal efficiency was expressed as a ratio of the number of sensitive isolates and the number of the isolates tested.

\section{RESULTS}

We evaluated the antifungal activity of the EOs at concentrations $0.5 \%, 5 \%$ and $30 \%$. The lowest tested concentration $(0.5 \%)$ was not sufficient to inhibit the growth of Malassezia; all the inhibition zones were $0 \mathrm{~mm}$ (data not shown).

Table 2 illustrates the antifungal activity of the EOs at a concentration of $5 \%$ against isolates and reference strain of M.pachydermatis. Table 3 shows the effect of EOs at a concentration of $30 \%$. Essential oils obtained from clove, cinnamon and oregano exhibited an excellent effectiveness against M.pachydermatis growth at $30 \%$ concentration. Clove and cinnamon EOs at a concentration of $5 \%$ had an antifungal effect on less than half of the isolates tested (38\% and $33 \%$, respectively). The EOs of satureja, tea tree, bergamot, lavender, juniper, sage, grapefruit, cedar, pine, chamomile and yarrow showed insufficient antifungal properties against M.pachydermatis in all concentrations.

All essential oils at a concentration of $0.5 \%$ were not sufficient to inhibit the growth of both the isolates and the reference strain (all the inhibition zones were $0 \mathrm{~mm}$ ), therefore these are not included in the table.

\section{DISCUSSION}

The essential oils can act as antibacterial agents against a wide spectrum of pathogenic bacterial strains including Listeria monocytogenes, L. innocua, Salmonella typhimurium, Escherichia coli, Shigella dysenteria, Bacillus cereus and Staphylococcus aureus. Plant extracts, especially EOs, may afford a potential alternative to synthetic antiviral drugs: they have virocidal properties against Herpes simplex I [10]. Several EOs can act also on various microscopic fungi, e.g. Aspergillus niger, Geotrichum candidum [26], Trichophyton rubrum, T.mentagrophytes, Microsporum canis, Epidermophyton floccosum [8], Candida albicans and Malassezia furfur [11].

According to the results of our study, the essential oils of clove, cinnamon and oregano in concentration of $30 \%$ showed excellent activity against M.pachydermatis. The formation of inhibition zones of cedar, chamomile, sage, grapefruit and tea-tree oil indicated their partial efficacy, however, based on the methodology they cannot be assessed as effective. 
Table 2. Effectiveness of essential oils at a concentration of $5 \%$ against Malassezia pachydermatis

\begin{tabular}{lccc}
\hline & \multicolumn{2}{c}{$\begin{array}{c}\text { Isolates } \\
(\mathrm{n}=18)\end{array}$} & Reference strain \\
\cline { 2 - 4 } Essential oil & $\begin{array}{c}\text { Inhibition zones } \\
{[\varnothing \pm \mathrm{SD}]}\end{array}$ & $\mathbf{E}(\mathbf{s s} / \mathbf{n})$ & $\begin{array}{c}\text { Inhibition zones } \\
{[\%]}\end{array}$ \\
\hline Clove & $16.94 \pm 5.97$ & $38 \%(7 / 18)$ & 18 \\
Cinnamon & $15.44 \pm 5.73$ & $33 \%(6 / 18)$ & 15 \\
Oregano & $13 \pm 2.86$ & $5 \%(1 / 18)$ & 14 \\
Satureja & $7.49 \pm 1.87$ & $0 \%$ & 0 \\
Cedar & $3.22 \pm 3.02$ & $0 \%$ & 8 \\
Chamomile & $3.61 \pm 3.44$ & $0 \%$ & 6 \\
Bergamot & 0 & $0 \%$ & 0 \\
Lavender & 0 & $0 \%$ & 0 \\
Grapefruit & 0 & $0 \%$ & 0 \\
Sage & 0 & $0 \%$ & 0 \\
Tea tree & 0 & $0 \%$ & 0 \\
Juniper & 0 & $0 \%$ & 0 \\
Pine & 0 & $0 \%$ & 0 \\
Yarrow & 0 & $0 \%$ & 0 \\
\hline
\end{tabular}

$\varnothing$ - average size of the inhibition zone in $\mathrm{mm}$; SD — standard deviation; E-Percentage of efficacy (number of sensitive strains/ number of samples tested); $s s$ - sensitive strains; $n$ - number of samples tested

Table 3. Effectiveness of the essential oils at a concentration of $30 \%$ against Malassezia pachydermatis

\begin{tabular}{lccc}
\hline & \multicolumn{2}{c}{$\begin{array}{c}\text { Isolates } \\
(\mathrm{n}=18)\end{array}$} & Reference strain \\
\cline { 2 - 4 } Essential oil & $\begin{array}{c}\text { Inhibition zones } \\
{[\varnothing \pm \mathrm{SD}]}\end{array}$ & $\begin{array}{c}\mathbf{E}(\mathbf{s s} / \mathbf{n}) \\
{[\%]}\end{array}$ & $\begin{array}{c}\text { Inhibition zones } \\
{[\mathrm{mm}]}\end{array}$ \\
\hline Clove & $41.67 \pm 4.81$ & $100 \%(18 / 18)$ & 44 \\
Cinnamon & $40.14 \pm 5.01$ & $100 \%(18 / 18)$ & 50 \\
Oregano & $38.8 \pm 4.45$ & $100 \%(18 / 18)$ & 52 \\
Satureja & $23.26 \pm 2.18$ & $16 \%(3 / 18)$ & 12 \\
Cedar & $11.94 \pm 1.89$ & $0 \%$ & 12 \\
Chamomile & $11.17 \pm 1.38$ & $0 \%$ & 12 \\
Bergamot & $8.44 \pm 1.67$ & $0 \%$ & 10 \\
Lavender & $6.55 \pm 4.32$ & $0 \%$ & 8 \\
Grapefruit & $10.78 \pm 2.39$ & $0 \%$ & 10 \\
Sage & $10.06 \pm 2.73$ & $0 \%$ & 14 \\
Tea tree & $8.44 \pm 4.87$ & $0 \%$ & 10 \\
Juniper & $5.55 \pm 3.26$ & $0 \%$ & 8 \\
Pine & $4.44 \pm 3.79$ & $0 \%$ & 6 \\
Yarrow & 0 & $0 \%$ & 0 \\
\hline
\end{tabular}

$\varnothing$ - average size of the inhibition zone in $\mathrm{mm}$; SD — standard deviation; $\mathrm{E}$ - percentage of efficacy (number of sensitive strains/ number of samples tested); ss - sensitive strains; $n$ - number of samples tested 
The antifungal effect of tea tree oil has also been reported by Carson et al. [5]. Studies investigating the mechanism of antifungal action have focused almost exclusively on Candida albicans as a model micro-organism. Similar to results found for bacteria, tea tree oil also alters the permeability of C.albicans cells.

Antifungal activity against M.pachydermatis was performed by Kim et al. [18] using disc-diffusion assays and well diffusion tests. The essential oils inhibited the growth of M.pachydermatis in a range from $0.5 \%$ to $1.0 \%$ concentrations. Thyme oil was found to be highly effective in inhibiting the growth of M.pachydermatis in a range from $0.125 \%$ to $0.0625 \%$, while marjoram and then tea tree oil exhibited lower inhibitory capacities [18]. Compared to our results, tea tree oil inhibited the growth of M.pachydermatis only at higher concentration (30\%), while the lower one was not sufficient.

In another study, the possible synergistic anti-Candida effect between tea tree, oregano and Pelargonium graveolens EOs and Amphotericin B was investigated. The antifungal activity was assessed using the agar dilution method in eleven strains of C.albicans, C. glabrata, C. guillermondi, C.krusei, C.parapsilosis and C.tropicalis. The results obtained indicated the occurrence of a synergistic interaction between the essential oils under study and Amphotericin B. P. graveolens essential oil appeared to be the most effective, inhibiting all the Candida species evaluated in their study [23]. Also, the results of our study demonstrated, that the efficiency of oregano EO was excellent (100\%) at higher concentration,

In our results, $100 \%$ efficiency was recorded by clove, cinnamon and these are comparable to the study of Rusenova and Parvanov [24]. In their study, twelve essential oils (thyme, clove, cinnamon, marjoram, tea tree, clary sage, peppermint, lemon, grapefruit, lemongrass, mandarin and oregano) were tested for inhibitory activity against some microorganisms of veterinary interest including Candida spp. and M.pachydermatis using the disc diffusion procedure. According to their results, the most potent essential oils were cinnamon, oregano, lemongrass and thyme.

Essential oils of various Juniperus species were tested by Cavaleiro et al. [6] against selected yeasts - Candida albicans, C. krusei and C. parapsilosis, molds - Aspergillus fumigatus and A.flavus and against dermatophytes - Microsporum canis, M. gypseum, Trichophyton rubrum, T. menta- grophytes and Epidermophyton floccosum. All essential oils inhibited dermatophyte strains, C.krusei, C.glabrata and C.albicans.

The antifungal action of various EOs against Aspergillus niger and Geotrichum candidum was also tested by Verma et al. [26]. By using different concentrations of EOs (5, 10, 20, 30, 40 and 50 ppm), it was concluded that clove, lemon, orange and peppermint oil, already at the lowest concentration, had activity comparable to ketoconazole in the same concentration, whereas the effect of castor, olive and cedar oil was inadequate.

\section{CONCLUSIONS}

The enormous development of chemical drugs is currently associated with the increasing emergence of serious adverse effects including drug-resistance. Traditional medicinal plants represent a reservoir of pharmacologically active substances, which can also be used in the treatment of infectious diseases due to their antimicrobial effects. The results of our study have revealed that essential oils of clove, cinnamon and oregano at concentrations of $30 \%$ inhibited the growth of Malassezia pachydermatis isolates (100\% efficiency), implying their potential use in the treatment of Malassezia infections in dogs. The confirmation of their potential antimicrobial effect indicates that these plants may be useful in combined therapy or creation of natural antifungal medications.

\section{ACKNOWLEDGEMENTS}

This study was supported by the Slovak Research and Development Agency under the contract APVV-15-0377.

\section{REFERENCES}

1. Batra, R., Boekhout, T., Guého, E., Cabañes, F. J., Dawson, T. L., Jr., Gupta, A.K., 2005: Malassezia Baillon, emerging clinical yeasts. FEMS Yeast Res., 5, 1101-1113.

2. Cabañes, F. J., Theelen, B., Castellá, G., Boekhout, T., 2007: Two new lipid-dependent Malassezia species from domestic animals. FEMS Yeast Res., 7, 1064-1076.

3. Cabañes, F. J., Veja, S., Castellá, G., 2011: Malassezia cunicu- 
li sp. nov., a novel yeast species isolated from rabbit skin. Med. Mycol., 49, 40-48.

4. Cabañes, F. J., Coutinho, S.D., Puig, L., Bragulat, M.R., Castellá, G., 2016: New lipid-dependent Malassezia species from parrots. Rev. Iberoam. Micol., 33, 92-99.

5. Carson, C. F., Hammer, K. A, Riley, T. V., 2006: Melaleuca alternifolia (Tea Tree) Oil: a Review of antimicrobial and other medicinal properties. Clin. Microbiol. Rev., 19, 50-62.

6. Cavaleiro, C., Pinto, E., Goncalves, M.J., Salgueiro, L., 2006: Antifungal activity of Juniperus essential oils against dermatophyte, Aspergillus and Candida strains. J. Appl. Microbiol., 100, 1333-1338.

7. Chiavassa, E., Tizzani, P., Peano, A., 2014: In vitro antifungal susceptibility of Malassezia pachydermatis strains isolated from dogs with chronic and acute otitis externa. Mycopathologia, 178, 315-319.

8. Chuang, P.H., Lee, C. W., Chou, J. Y., Murugan, M., Shieh, B. J., Chen, H. M., 2007: Anti-fungal activity of crude extracts and essential oil of Moringa oleifera Lam. Biores. Technol., 98, 232-236.

9. Clinical and Laboratory Standards Institute, 2009: M44A2. Method for antifungal disc diffusion susceptibility testing of yeast. Approved Guideline, 2nd edn., 1-23.

10. Edris, A.E., 2007: Pharmaceutical and therapeutic potentials of essential oils and their individual volatile constituents: A review. Phytotherapy Res., 21, 308-323.

11. Ferhout, H., Bohatier, J., Guillot, J., Chalchat, J.C., 1999: Antifungal activity of selected essential oils, cinnamaldehyde and carvacrol against Malassezia furfur and Candida albicans. J. Essent. Oil Res., 11, 119-129.

12. Gaitanis, G., Magiatis, P., Hantschke, M., Bassukas, I.D., Velegraki, A., 2012: The Malassezia genus in skin and systemic diseases. Clin. Microbiol. Rev., 25, 106-141.

13. Gaitanis, G., Velegraki, A., 2006: Verifiable single nucleotide polymorphisms of the internal transcribed spacer 2 region for the identification of 11 Malassezia species. J. Dermatol. Sci., 43, 214-217.

14. Guillot, J., Bond, R., 1999: Malassezia pachydermatis: A review. Med. Mycol., 37, 295-306.

15. Hammer, K. A., Carson, C. F., Riley, T. V., 2000: In vitro activities of ketoconazole, econazole, miconazole and Melaleuca alternifolia (Tea Tree) oil against Malassezia species. Antimicrob. Agents Chemother., 44, 467-469.
16. Kalemba, D., Kunicka, A., 2003: Antibacterial and antifungal properties of essential oils. Cur. Med. Chem., 10, 813-829.

17. Kaneko, T., Makimura K., Abe, M., Shiota, R., Nakamura, Y., Kano, R., et al., 2007: Revised culture-based system for identification of Malassezia species. J. Clin. Microbiol., 45, 3737-3742.

18. Kim, J. Y., Olivry, T., Son, W. G, 2012: Characteristics of Malassezia pachydermatis isolated from dogs and antifungal effect of essential oils. J. Vet. Clin., 29, 141-147.

19. Mauldin, E. A., Scott, D. W., Miller, W. H., Jr., Smith, C. A., 1997: Malassezia dermatitis in the $\operatorname{dog}$ - A retrospective histopathological and immunopathological study of 86 cases (1990-1995). Vet. Dermatol., 7, 191-202.

20. Nardoni, S., Mugnaini, L., Pistelli, L., Leonardi, M., Sanna, V., Perrucci, S., et al., 2014: Clinical and mycological evaluation of an herbal antifungal formulation in canine Malassezia dermatitis. J. Mycol. Med., 24, 234-240.

21. Pistelli, L., Mancianti, F., Bertoli, A., Cioni, P. L., Leonardi, M., Pisseri, F., et al., 2012: Antimycotic activity of some aromatic plants essential oils against canine isolates of Malassezia pachydermatis: An in vitro assay. The Open Mycol. J., 6, 17-21.

22. Raut, J.S., Karuppayil, S. M., 2014: A status review on the medicinal properties of essential oils. Ind. Crops. Prod., 62, 250-264.

23. Rosato, A., Vitali, C., Gallo, D., Balenzano, L., Mallamaci, R., 2008: The inhibition of Candida species by selected essential oils and their synergism with amphotericin B. Phytomed., $15,635-638$.

24. Rusenova, N., Parvanov, P., 2009: Antimicrobial activities of twelve essential oils against microorganisms of veterinary importance. Trakia J. Sci., 7, 37—43.

25. Váczi, P., Čonková, E., Marcinčáková, D., Sihelská, Z., 2016: Effectiveness of essential oils on Malassezia pachydermatis. Folia veterinaria, 59, 12-17.

26. Verma, R. K., Chaurasia, L., Kumar, M., 2011: Antifungal activity of essential oils against selected building fungi. Indian J. Nat. Prod. Resour., 2, 448-451.

27. Weiler, C. B., Kunz de Jesus, F. P., Nardi, G. H., Loreto, E. S., Santurio, J.M., Coutinho S.D. A., et al., 2013: Susceptibility variation of Malassezia pachydermatis to antifungal agents according to isolate source. Braz. J. Microbiol., 44, 174-178.

Received February 27, 2018

Accepted May 15, 2018 